\title{
The Army Personnel Research Committee (APRC) and the Army
}

In a small professional army such as ours we have to provide the conditions for soldiers to operate at maximum efficiency and at the lowest possible risk. Courage, endurance and skill are wasted if they are not backed up by first-class equipment, training and protection. In order to be effective, soldiers must be carefully selected, well led, fit and capable of handling weapons confidently. To carry out their tasks they must be adequately clothed and protected both against enemy action and against the rigours of climate, which may range from the tropics to the Arctic. Every aspect of the army environment affecting performance offers important opportunities for research, from the physical dangers of the battlefield to the waterproof qualities of the army boot.

The term 'human factors' (HF) embraces all these elements and the aim of $\mathrm{HF}$ research is to provide answers to problems that advances in technology are making ever more complex. HF research is not an activity that concerns only the armed services; it is increasingly require in industry and is involved in many problems of everyday life. From a scientific point of view HF research is a challenging area, involving among others the disciplines of physiology, psychology, human engineering, information theory and epidemiology.

The Army Personnel Research Committee (APRC) (Chairman Professor J C Waterlow FRS) was established by the Medical Research Council (MRC) in 1953, replacing its fore-runner the Military Personnel Research Committee which dated back to 1940 . Its role is to advise the Ministry of Defence on biological, medical, physiological, ergononic, psychological and sociological matters affecting the health and efficiency of Army personnel. In practice its main function is to provide independent advice on the Army's programme of 'human factors' research. Most of this research is done at the Army Personnel Research Establishment (APRE) at Farnborough, but some is carried out for APRE under contract in university departments and industry. The APRC operates through three panels, corresponding to the divisions in which APRE is organized: Personnel Psychology (Chairman Professor A Williams, City University Business School); Applied Physiology (Chairman Professor P H Fentem, University of Nottingham) and Operator Performance (Chairman Professor $\mathbf{J} \mathbf{T}$ Reason, University of Manchester). Members of the Panels regularly visit APRE and maintain close contact with the Heads of Divisions and their staffs. This mode of working has proved successful and has resulted in establishing productive links with related work in University departments and MRC units. When appropriate, ad hoc $\stackrel{\vec{F}}{\stackrel{\vec{P}}{+}}$ meetings are arranged to consider special topics.

Personnel Psychology (PP). The work of this Division $\frac{\bar{\sigma}}{\bar{m}}$ has two main thrusts - selection and training. The $\underset{\widetilde{\sigma}}{\overrightarrow{0}}$ Division helps to ensure that the Army obtains and 0 makes the best use of the right people for its very wide range of tasks. It is also important to avoid wastage. $A_{\vec{O}}$ soldier, after he first signs on, is allowed six months to decide whether he is suited to a career in the Army. If he $\vec{\omega}$ opts out, this represents a lost investment in terms of both money and army time. A great deal thus depends on the effectiveness of the processes of selection and recruitment. Research in this area is concerned with $\vec{\omega}$ extending and refining methods of psychometric testing and seeing how they can be applied in a practical way. 오 Demographic trends will provide a major challenge to음 methods of selection. It is forecast that over the next fewo decades fewer members of our population will be of the right age-group for entering the Services. The Arnoy 7 already contains a substantial proportion of women al他 it is likely that this proportion will increase.

The soldier, once recruited, has to be trained. three divisions of APRE are concerned with sonke $\rightarrow$ aspects of training, but the PP Division has the masi 8 responsibility. Since the opportunities for training wi modern weapons under real-life conditions a⿳亠丷厂犬. restricted, it is necessary to devise simulators which c⿻্乛亅n be used for developing perceptual, psychomotor and cognitive skills without the cost or risk of the real-life situation. Here there is a dilemma: the closer the $\mathscr{Q}$ simulator is to mimicking a particular condition, the $\overrightarrow{\overrightarrow{0}}$ greater the reassurance to the trainee, but the less likely 3 it is then to be versatile and cost-effective. There are general questions which have applications far outside? the field of defence, such as: how transferable are the knowledge and skills acquired by training? How far do real-life factors such as fatigue and fear affect cognition and the ability to make even simple judgements, such as estimating the speed of an approaching vehicle?

Applied Physiology (AP). The overall aim of the AP Division is to find ways of maintaining a soldier's performance of many different tasks over a wide range of physical environments. Performance may be affected $ᄋ$ in many ways. First and foremost comes physical fitness, even in these days of mechanized armies. This has two음 components, both of which need to be considered - $\rightarrow$ maximum work output and endurance. Next there are the classical effects of climate; soldiers have to be able to $N$ operate in extremes of heat and cold.

A problem that constantly comes up is how to achieve $\stackrel{N}{\circ}$ the best balance between performance and protection. $c$ 
Personal equipment such as body armour, respirators and protective clothing increases the weight that a soldier has to carry and this is one of the main factors which reduces his mobility and loadbearing capacity. Personal equipment also impedes the loss of heat, so that a man's endurance time in a hot climate may be seriously curtailed.

Other factors that influence performance are fatigue, loss of sleep, anxiety and fear. A subject of much importance and great difficulty is to find ways of measuring the intensity of such stresses under different conditions. Fatigue and deprivation of sleep can be produced experimentally but it is clearly not possible to reproduce the multiple and often interacting psychological stresses of battlefield conditions.

Another problem with which a modern soldier has to cope, to a far greater extent than his predecessors, is that of noise and vibration. Army vehicles provide an inherently noisy environment; with this comes the problem of intelligible communication while hearing is protected. Unlike in some industries, lip-reading is not a feasible solution for soldiers. The extremely high noise levels produced by both vehicles and weapons have stimulated the investigation of novel electronic methods of noise reduction, such as Active Noise Reduction (ANR) in noise-excluding headsets. Levels of vibration in unsprung armoured vehicles are also severe and may be enough to cause passengers to try to keep their feet off the floor! Little is known about the degree of stress produced by long continued vibration.

The AP Division also includes a section concerned with occupational health in the Army. A subject currently being investigated is the high frequency of lower limb injuries sustained by new recruits during their initial training period. This is a problem of wider concern, as there is an increasing tendency for this type of injury to occur during training in amateur and professional sportsmen and women.

These examples may suffice to show that the AP Division is tackling basic problems in human physiology that are relevant to many occupations outside the artificially regulated office environment, particularly to those operating in stressful and potentially hazardous conditions, such as miners, firefighters, sailors and workers in chemical and nuclear establishments.

Operator Performance (OP). The work of this division is directed towards the integration of personnel into ever more complex military systems. One major area of research is information processing. The battlefield is an environment rich in information, which derives from sources with greater or lesser degrees of validity. The aim is to find the optimum way of combining and displaying this information to avoid overloading the operator and to enable decisions to be taken quickly and correctly. This is a problem common to fire-control systems, target designation and tracking, and command and control systems. The study of the human factors aspects of these systems requires the development of increasingly sophisticated simulators.

A related subject is perception and the ability to detect and interpret images, particularly under stress. IIR many situations soldiers have to rely on indirect vision for assessing the operational situation. Many of the instruments use VDU presentation and research is needed on the best type of display in terms of colour $\overrightarrow{e_{0}}$ contrast, texture of the image, etc. Any display systen will impose on the operator some display management tasks, many modern information systems have a strong geographical component and are likely to be based on computerized digital maps. Given the importance of these mapping systems in battlefield operations it is essential that their management and use should be made as effective as possible.

Many tasks are performed by soldiers working iff small teams, such as the crews of tanks and guns Research is needed on how to balance the allocation of tasks to ensure that operations are as smooth an $\bar{\phi}$ efficient as possible and matched to the capacity and skills of the team members.

For all these activities greater detail is required on the way in which performance is affected by continuou? operations, of up to 60 hours duration. With devices that make night vision possible, operations do not. necessarily come to a stop after night falls, as to a vōrn large extent they did in the past. This not only increages the strain on soldiers, but poses new problems $\overrightarrow{\mathrm{D}} 0$ f organizing changes in shifts.

The OP Division is also responsible for Human Facford research in the Army Air Corps. The cause of accideantto is an obvious subject for concern. An important speculative area for research is the definition of potentap 'bad days' for pilots, when they might be expected to at greater than normal risk. This subject has importan implications for civilians, such as commercial pilots an police officers.

As the preceding paragraphs show, 'human factors research at APRE has to deal with a wide range o\$ practical questions posed by different branches of the Army, often requiring urgent answers. At the same time. the APRC has emphasized the need for an ongoing programme of longer-term or 'strategic' research, mucF: of which is relevant to industrial and other civilia problems, as many examples have shown. Long-terno research is essential, not only to underpin the work oo immediate tasks, but also to provide the challenge and intellectual satisfaction, without which scientists of ability will not give of their best. This view has been accepted by the Ministry of Defence and there is ever? intention, as far as circumstances allow, to expand the base of strategic research, of which a number of examples have been given in this article.

The Army Personnel Research Committee i폰. particularly concerned with promoting strategif research. It is therefore an important part of its function to foster links between APRE staff and the academi community, and to help in the recruitment of ablew 
research workers. The history of science provides innumerable examples of how the need to solve a practical problem has led on to ideas of general interest and theoretical importance. 'Human factors' research offers many challenges that can contribute to the development of knowledge and improvement of the quality of the working environment for everyone, not only the Army.

\section{Footnote}

To stimulate strategic research, the Joint Research Council/MOD Research Grant Scheme was set up in 1985 and revised in 1988. The APRC is anxious to encourage applications to the Medical Research Council (MRC) for research into appropriate areas of work in the 'human factors' field. Such areas of particular interest to the MOD are:

- Behavioural sciences, including man-machine interaction, ergonomics, computer-based training and intelligent systems for training.
- Human applied physiology, in particular the maintenance of effectiveness in hostile environments.

- Physical and mental stress, and degradation of performance.

- Noise and vibration.

- Environmental and survival medicine.

Potential applicants may find it helpful to contact $\vec{\Phi}$ members of the APRC on possible research projectso suitable for this scheme. If so, initial enquiries may be made to Miss Roberta Withnall, Medical Research. Council, 20 Park Crescent, London W1N 4AL (tel 01- $\overrightarrow{\vec{\omega}}$ 6365422 ). Copies of a booklet describing the scheme in detail are available from the MRC Grants Section (address as above).

\section{ACADEMIC ACHIEVEMENTS}

$\operatorname{MSc}($ Occ Med)

AFOM

MFCM

MRCP

MS (Southampton)

DLO
Lt Col C G Batty, RAMC

Lt Col L P Lillywhite, RAMC

Lt Col C G Batty, RAMC

Lt Col L P Lillywhite, RAMC

Major S A St J Miller, RAMC

Captain N C Hepburn, RAMC

Major S D Scott, RAMC

Major T R Whelan, RAMC 